\title{
Gambling Problems among Community Cocaine Users
}

Magali Dufour ${ }^{1}$, Noël Nguyen ${ }^{1}$, Karine Bertrand ${ }^{1}$, Michel Perreault ${ }^{2,3}$, Didier Jutras-Aswad ${ }^{4,5}$, Adèle Morvannou ${ }^{1}$, Julie Bruneau ${ }^{4,6}$, Djamal Berbiche ${ }^{1}$, Élise Roy ${ }^{1,7}$

${ }^{1}$ Faculty of Medicine and Health Sciences, Université de Sherbrooke, Campus de Longueuil 150 Place Charles-Le Moyne, Room 200, Longueuil, QC J4K 0A8, Canada

${ }^{2}$ Douglas Mental Health Institute, Montreal, QC, Canada

${ }^{3}$ Department of Psychiatry, McGill University, Montreal, QC, Canada

${ }^{4}$ Research Center, Centre Hospitalier de l'Université de Montréal (CRCHUM), Montreal, QC, Canada

${ }^{5}$ Department of Psychiatry, Université de Montréal, Montreal, QC, Canada

${ }^{6}$ Department of Family Medicine, Université de Montréal, Montreal, QC, Canada

${ }^{7}$ Institut national de sante' publique du Québec, Montreal, QC, Canada

\begin{abstract}
Cocaine use is highly prevalent and a major public health problem. While some studies have reported frequent comorbidity problems among cocaine users, few studies have included evaluation of gambling problems. This study aimed to estimate the prevalence of gambling problems and compare those who were at-risk gamblers with nonproblem gamblers in terms of mental health problems, substance use problems, and some risk factors (i.e. family antecedents, erroneous perceptions and coping strategies) among individuals who smoke or inject cocaine. METHOD: A total of 424 smoked or injected cocaine users recruited through community-based programs in Montreal, Quebec completed the questionnaire, including the Canadian Pathological Gambling Index, the Composite International Diagnostic Interview (CIDI), the CAGE, and the Severity Dependence Scale (SDS). RESULTS: Of the sample, $18.4 \%$ were considered at-risk gamblers, of whom $7.8 \%$ had problems gambling and $10.6 \%$ were moderate-risk gamblers. The at-risk group was more likely to have experienced a recent phobic disorder and alcohol problems than the non-problem group. A multivariate analysis showed that, compared to those who were non-problem gamblers, the at-risk ones were more likely to have lost a large sum of money when they first started gambling, believed that their luck would turn, and gambled in reaction to painful life events. These results indicate the need to include routines for screening to identify gambling problem among cocaine users.
\end{abstract}

Keywords: Cocaine user - Gambling problem - Addiction - Substance abuse - Comorbidity - Coping strategies

\section{Introduction}

In 2011, 17 million people worldwide had used cocaine in the last year. A large proportion of these users lived in North America, a continent where the demand for cocaine is highest (UNODC World Drug Report 2014). In Canada, cocaine use affects approximately $1.1 \%$ of individuals above the age of 14 years old (CADUMS 2012). 
Cocaine misuse contributes to the development of several psychosocial and health consequences (Lévesque et al. 2014; Riezzo et al. 2012; Smith et al. 2014) including social dysfunction, unemployment, mental health problems, HIV and hepatitis C viral infections (Cunha et al. 2010; Hser et al. 2004; Karila et al. 2009). It is therefore important to better characterize cocaine users in order to develop effective interventions to reduce the health burden related to problematic cocaine use (McRae et al. 2007).

Mental health problems are a major concern among individuals addicted to cocaine (Kandel et al. 2001; Vergara-Moragues et al. 2012). In fact, between 35-65 \% of cocaine dependent users are diagnosed with a, or multiple, mental health issue(s) during their lifetime (Falck et al. 2002; Herrero et al. 2008; Vergara-Moragues et al. 2012). When compared with those who do not have psychiatric comorbidity, cocaine dependent users who have dual diagnoses are more likely to abandon their treatment and report less improvement (Gonzalez-Saiz et al. 2009; King et al. 2014). While comorbidity between cocaine dependence and mood disorders (Conner et al. 2008; VergaraMoragues et al. 2012), alcohol dependence (Ford et al. 2009), post traumatic stress disorder (PTSD) (Saunders et al. 2015), attention deficit hyperactivity disorder (ADHD) (Daigre et al. 2013), psychotic disorders (Vergara-Moragues et al. 2012) and some personality disorders (Ford et al. 2009) have been previously documented, few studies have focused on problem gambling (PG) within these populations.

Problem gambling has been linked to a variety of harmful mental and physical health consequences, as well as a wide variety of problems such as high criminality and homelessness (Blaszczynski and Silove 1996; Shaffer et al. 2004; Stein et al. 2012; Turner et al. 2009). These consequences make PG an important public health problem, especially for more vulnerable populations (Gainsbury et al. 2014; Korn and Shaffer 1999; Papineau 2010; Shaffer and Hall 2001) such as individuals with a history of problematic substance use. Indeed, within this vulnerable population, PG is 8 to 24 times the prevalence reported for the general population (Cowlishaw et al. 2014; Cowlishaw and Hakes 2015; Cunningham-Williams et al. 2000; Fernandez-Montalvo et al. 2012; Mathias et al. 2009; Toneatto and Brennan 2002). The few studies that have focused on cocaine users, all of which were carried out in drug treatment centers, have found prevalence rates of problem gambling among cocaine dependent users ranging from 8 to $15 \%$ (Hall et al. 2000; Steinberg et al. 1992; Toneatto and Brennan 2002).

This comorbidity between PG and substance dependence has significant repercussions on mental health and living conditions (Cunningham-Williams et al. 2000; Mathias et al. 2009). In fact, gamblers who also have another form of dependence (e.g. alcohol or drugs) present a more severe clinical picture when entering treatment and report more mental health problems when compared with those who have one dependence problem (Arseneault et al. 2001; Cunningham-Williams et al. 2000; Feigelman et al. 1998; Fernandez-Montalvo et al. 2012; Hall et al. 2000; Liu et 
al. 2009; Mathias et al. 2009; Petry 2007). Treatment studies concerning cocaine users have found those with gambling problems to be more likely unemployed, to have had a higher prevalence of antisocial personality disorders and more frequent issues with the justice system (Hall et al. 2000; Toneatto and Brennan 2002). However, these results do not provide much needed information concerning those active cocaine users neither contributed to understand which risk factors are associated with gambling problems.

In an effort to improve our understanding of problem gambling and comorbid mental disorders in a population rarely studied, this exploratory study aims to investigate gambling behaviours, characteristics (sociodemographic) of problem gamblers, and some risk factors (family addiction antecedents, first gambling experience, erroneous perceptions and avoidant coping strategies) in a community-based sample of cocaine users.

\section{Method}

A prospective cohort study of mental health disorders, HIV and hepatitis C virus (HCV) infections among street-based cocaine users called the COSMO project was carried out in Montréal, Canada (Lévesque et al. 2014). Analyses were run using data pertaining to gambling behaviors and risk factors (family addiction antecedents, first gambling experience, erroneous perceptions and avoidant coping strategies) collected during one visit over the course of the study. All participants gave explicit consented to take part in the study and ethics approval for the study was provided by the 'Comité d'éthique de la recherche en santé chez l'humain du Centre hospitalier universitaire de Sherbrooke'.

\section{Participants and procedure}

To take part in the cohort study, participants must have used cocaine in the last month, either by smoking crack or by injection. Other eligibility criteria included being at least 14 years old, English- or French- speaking, the ability to provide informed consent and complete an interviewer-administered questionnaire, and having plans to stay in the Montréal area in the following year. Recruitment took place between June 2011 and May 2014. Participants were recruited in community-based programs located in downtown Montréal (Québec) including: day programs for the homeless, various shelters, and needle exchange programs. Recruitment was carried out by study interviewers who visited collaborating community-based programs on a weekly basis except for the smallest ones for which visits were scheduled monthly. Cocaine users willing to participate in the study were invited to the research office located close to the recruitment sites. Participation included baseline and follow-up appointments every three months for 18 months. At each visit, participants were asked to sign a consent form, provide contact information, and complete an 
interviewer-administered questionnaire. Participants received financial compensation of CAD 30 at the end of each interview.

\section{Materials}

Interviews took approximately 90 and 120 minutes to complete and covered various themes related to the objectives of the cohort study. To avoid unduly prolonging visits, some questions were completed during only one visit during the study period. For example, questions assessing diagnoses of mental health disorders were completed only at baseline while questions on gambling problems and risk factors were asked two visits later at time 3 . All other questions were asked at each visit. Variables typically associated with problematic gambling examined including: socio-demographic characteristics, gambling activities, gambling problems, drug and alcohol consumption, and various risk factors (i.e. family history of addiction, first gambling experience, erroneous perceptions and avoidant coping strategies) (Ferris and Wynne 2001; Welte et al. 2004).

Sociodemographic characteristics: these variables included age, gender, ethnicity (born in Canada versus outside of Canada), level of education (less than high school versus higher level), homelessness (defined as having lived or slept at least once in a shelter or in any place not intended for housing in the past 3 months), having an unstable income (defined as having a marginal or criminal source of income in the past 3 months).

Gambling activity and Problems: participation, in the last 12 months, to eighteen types of gambling activities was examined (Ferris and Wynne 2001). Severity of gambling problems was evaluated using the 9-item Problem Gambling Severity Index (PGSI), a quantitative sub-section of the Canadian Problem Gambling Index (CPGI) (Ferris and Wynne 2001). The PGSI consists of 9 items with answers reported on a 4-point Likert scale ('Never'; 'Sometimes'; 'Most of the time'; 'Almost always'). The PGSI demonstrates strong internal validity and reliability, as well as satisfactory temporal reliability (Currie et al. 2013). The instrument was used to create four categories of players: no risk (score of 0 ); low risk (score of 1-2); moderate risk (score of 3-7); and problem gambler (score of 827).

Risk Factors: When designing the CPGI, authors Ferris and Wynne (2001) found a number of variables pertaining to respondents' predispositions and environment that, although peripheral to the core construct of problem gambling, were associated with the development and severity of gambling problems. These variables include: 1) 
first gambling experience (i.e. 'Do you remember a big win when you first started gambling?'; 'Do you remember a big loss when you first started gambling?'); 2) family addiction antecedents (i.e. 'Has anyone in your family ever had a gambling problem?'; 'Has anyone in your family ever had an alcohol or drug problem?'); 3) erroneous perception (i.e. Chance: 'After losing many times in a row, you are more likely to win'; Strategy: 'You could win more if you used a certain system or strategy'); 4) the use of psychoactive substances while gambling (i.e. 'In the 12 last months, have you used alcohol or drugs while gambling?'; 'In the last 12 months, have you gambled while drunk, or high?'); 5) avoidant coping strategies (i.e. 'In the last 12 months, if something painful happened in your life, did you have the urge to gamble?'; 'In the last 12 months, if something painful happened in your life, did you have the urge to have a drink?'; 'In the last 12 months, if something painful happened in your life did you have the urge to use drugs or medication?').

Problematic substance use: problematic alcohol consumption was assessed using the CAGE questionnaire (Mayfield et al. 1974), a quick yet sensitive and specific instrument for screening alcohol use disorder (Bernadt et al. 1982). Two positive responses on this instrument indicate a high probability of problematic alcohol consumption. Severity of cocaine dependence was estimated using the severity of dependence scale (SDS) (Gossop et al. 1995). The SDS is a five-item tool measuring the intensity of dependence to a drug over the past 3 months. The score ranges between 0 and 15. Cocaine dependence was determined by a SDS score of 4 or higher (Gonzalez-Saiz et al. 2009).

Mental health disorders: questions regarding past year diagnosis of one or multiple primary mental disorders were taken using two instruments. Psychotic (delusional disorder, brief psychotic disorder and schizophrenic disorder) and affective disorders (major depression, bipolar disorders and dysthymia) were assessed using the World Mental Health Composite International Diagnostic Interview (CIDI) version 2.1 (Kessler and Ustun 2004). Anxiety disorders (panic disorders, phobic disorder, generalized anxiety disorder) were assessed using the CIDIS developed by Kovess, Fournier, Lesage, Lebigre, and Caria (2001). Both instruments used are well-validated tools that can be administered by lay interviewers to produce psychiatric diagnoses according to the fourth version of the Diagnostic and Statistical Manual of Mental Health Disorders published by the American Psychiatric Association (2000).

\section{Analyses}


Analyses were conducted using data from 424 participants who completed the questionnaire on gambling behaviours and risk factors, representing $70 \%$ of the 605 participants participating in the COSMO project. Respondents had sociodemographic characteristics similar to the total sample of COSMO. Descriptive statistics were employed to characterize the study population, including means or medians with corresponding standard deviation or interquartile ranges (IQR) for continuous variables, and frequency distributions for categorical variables. Based on individual PGSI score, the sample was divided into two categories: at-risk gamblers group (moderate risk and problem gamblers) and non-problem gamblers group (non gamblers and low risk gambling). Pearson's chi-square test and when appropriate Fischer's exact test were used to compare gambling activities between the two groups.

To identify independent correlates of at-risk gambling behaviours, co-variables pertaining to sociodemographics, diagnoses of mental health disorders and risk factors were examined using logistic regression analyses. Covariables with a p-value $\leq 0.05$ in univariate analyses were considered in the multivariate linear regression model. The standard method of entry (the enter method) was used, i.e. all independent variables were entered into the equation at the same time. This method is an appropriate analysis when dealing with a small set of predictors and when the researcher does not know which independent variables will create the best prediction equation (Tabachnick and Fidell 2001). The final model included significant variables at a level alpha $\leq 0.05$. Statistical analyses were performed using IBM SPSS Statistics for Windows, Version 19.0. (Armonk, NY: IBM Corp) and SAS version 9.3 (SAS Institute, Cary NC).

\section{Results}

\section{Population characteristics}

Of the 424 participants, $92.9 \%$ reported smoking crack and $59.6 \%$ reported injecting crack/cocaine. The majority were men $(87.2 \%)$ and the mean age was 40.46 years old $(\mathrm{SD}=10.70)$. Most participants reported at least one episode of homelessness in the last three months (65.3\%), were born in Canada (94.8 \%), had more than higher level of education $(52.1 \%)$ and reported an unstable source of income $(70.5 \%)$.

\section{Gambling activities and gambling problems}

Gambling was common among participants, with 240 individuals (56.6\%) reporting participation in at least one gambling activity in the previous 12 months. According to overall PGSI scores, 162 out of 424 participants (38.2 \%) were non-problem gamblers including $135(31.8 \%)$ who were no risk and 27 (6.4\%) low-risk gamblers, 
while $78(18.4 \%)$ were at-risk gamblers including $45(10.6 \%)$ moderate gamblers and $33(7.8 \%)$ problem gamblers.

The at-risk $(n=78)$ and non-problem groups $(n=346)$ were similar with respect to age (mean age : 42 years old and 41 years old respectively, $p=.970)$, recent episode of homelessness $(62.8 \%$ and $59.9 \%, p=.641)$, ethnicity (93.6 and 95.1, $p=0.590$ ), level of education (less than high school, 46.5 and 53.8, $p=.244$ ), and reporting an unstable source of income $(70.8$ and $69.2, p=.782)$. However, the at-risk group had a slightly greater proportion of male participants than the non-problem group (94.9\% and $85.8 \%, p=.03)$.

The three most frequently reported gambling activities were buying lottery tickets (34.2\%), buying instant win or scratch tickets $(31.6 \%)$, and playing video lottery terminals (VLTs) in bars (26.0\%) (Table 1). No matter the activity, at-risk gamblers were more likely to play than non-problem gamblers. For the at-risk group, the three most frequent gambling activities were playing VLTs in bars $(71.8 \%)$, buying lottery ticket $(62.8 \%)$, buying instant win or scratch tickets $(59.0 \%)$ and the three most gambling activities in which they spent money were slot machines in a casino $(M=476.4)$, VLTs in bars $(M=267.8)$, and poker in a casino $(M=265.0)$.

Table 1 Participation to gambling activities in the past 12 months among all gamblers, at-risk and non-problem gamblers

\begin{tabular}{lcccc}
\hline Gambling activities & \% sample & $\begin{array}{c}\text { \% of non- } \\
\text { problem group } \\
(n=346)\end{array}$ & $\begin{array}{c}\text { \% of at-risk } \\
\text { group } \\
(n=78)\end{array}$ & $p$ - value \\
\hline Lottery tickets & 34.2 & 27.7 & 62.8 & $.000^{* * *}$ \\
Instant win or scratch tickets & 31.6 & 25.4 & 59.0 & $.000^{* * *}$ \\
Horse races & 1.9 & 0.6 & 5.1 & $.002^{* *}$ \\
Bingo & 1.7 & 1.4 & 3.8 & .160 \\
Slot machines in a casino & 3.5 & 2.0 & 10.3 & $.000^{* * *}$ \\
Poker in a casino & 2.1 & 0.9 & 7.7 & $.000^{* * *}$ \\
Black jack in a casino & 1.4 & 0.3 & 6.4 & $.000^{* * *}$ \\
Roulette in a casino & 1.2 & 0.3 & 5.1 & $.000^{* * *}$ \\
Keno in a casino & 1.2 & 0.6 & 3.8 & $.016^{* *}$ \\
Video lottery terminals (VLTs) in & 26.0 & 15.7 & 71.8 & $.000^{* * *}$ \\
bars & 1.7 & 1.2 & 3.8 & .092 \\
Sports lottery & 0.2 & 0.0 & 1.3 & $.035^{*}$ \\
Internet gambling & 1.2 & 0.9 & 2.6 & .211 \\
Poker in poker rooms & 5.7 & 3.5 & 15.4 & $.000^{* * *}$ \\
Poker within friends & & & & \\
\hline
\end{tabular}

$* p<.05, * * p<.01$, *** $p .001$

\section{Mental Health Disorders and Problematic Substance use}


Results of univariate analyses only yielded significant differences for phobic disorders and alcohol problems (CAGE score) (Table 2). Specifically, the at-risk group was more likely to have experienced recent phobic disorder and to have a CAGE score equal to or higher than 2.

Table 2 Recent mental health disorders for gambling problems among at-risk and non-problem gamblers

\begin{tabular}{|c|c|c|c|}
\hline Recent mental health disorders ${ }^{\S}$ & $\begin{array}{c}\% \text { non-problem group } \\
(n=346)\end{array}$ & $\begin{array}{c}\% \text { at-risk group } \\
(n=78)\end{array}$ & OR $(95 \% \mathrm{CI})$ \\
\hline \multicolumn{4}{|l|}{ Any anxiety disorder } \\
\hline Panic disorder & 17.9 & 20.5 & $1.18(0.64-2.19)$ \\
\hline Phobic disorder & 31.5 & 44.9 & $1.77(1.07-2.92)^{*}$ \\
\hline Generalized anxiety disorder & 15.0 & 20.5 & $1.46(0.78-2.72)$ \\
\hline \multicolumn{4}{|l|}{ Any affective disorder } \\
\hline Major depression & 18.8 & 19.5 & $1.05(0.56-1.95)$ \\
\hline Bipolar disorder & 8.4 & 7.8 & $0.92(0.37-2.31)$ \\
\hline Dysthymic disorder & 4.9 & 3.8 & $0.77(0.22-2.71)$ \\
\hline \multicolumn{4}{|l|}{ Any psychotic disorder } \\
\hline Delusional disorder & 0.3 & 0.0 & - \\
\hline Brief psychotic disorder & 0.0 & 0.0 & - \\
\hline Schizophrenic disorder & 1.2 & 3.8 & $3.42(0.75-15.6)$ \\
\hline \multicolumn{4}{|l|}{ Problematic substance use } \\
\hline Alcohol problem & 61.6 & 76.9 & $2.08(1.18-3.68)^{* *}$ \\
\hline SDS & 82.3 & 84.4 & $1.17(0.59-2.29)$ \\
\hline
\end{tabular}

$\S$ last 12 months, $\mathrm{OR}=$ odds ratio, $* p<.05, * * p<.01$

\section{Risk factors for gambling problems}

Univariate analyses of the risk factors showed statistically significant difference for seven of twelves risk factors (Table 3). Specifically, at-risk individuals, when compared to non-problem gamblers, were more likely to have won a large sum of money when they first started gambling, to have lost a large sum of money when they first started gambling, to have consumed alcohol or drugs while gambling, to have gambled under the influence of such substances, to have gambled in reaction to a painful life event, to have consumed alcohol in reaction to a painful life event and to have an erroneous perception of chance.

Table 3 Risk factors for gambling problems among at-risk and non-problem gamblers

\begin{tabular}{lccc}
\hline & $\%$ non- & $\%$ at-risk & OR (95\% CI) \\
Risk factors & problem group & group & $(n=78)$
\end{tabular}

Have won a large sum when first started gambling

$46.9 \quad 76.6 \quad 3.71(2.01-6.84) * * *$


Have lost a large sum when first started gambling

Gambling problems in family

Alcohol or drug problems in family

Have used alcohol or drugs while gambling

Have gambled under the influence of alcohol or drugs

Avoidant coping strategies:

Have had the urge to gamble in reaction to a painful event

Have had the urge to have a drink in reaction to a painful event

Have had the urge to use drugs in reaction to a painful event

Erroneous perceptions:

Chance: After losing many times in a row, you are more likely to win

Strategy: You could win more if you used a certain system or strategy

$\mathrm{OR}=$ odds ratio, $* p<.05, * * * p<.001$
19.1

35.7

74.7

38.9

45.1

1.9

$33.83(9.88-115.81) * * *$

52.5

74.7

10.2

13.8
39.0

67.9

$1.92(1.09-3.38)^{*}$

82.1

36.0

$1.01(0.60-1.80)$

$1.67(0.83-3.35)$

$5.55(2.97-10.30) * * *$

$6.1(0.92-5.30) * * *$

83.3$$
\text { ) }
$$$$
82
$$
$1.55(0.79-3.05)$

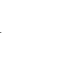

$29.5 \quad 3.69(1.81-7.50) * * *$

$23.1 \quad 1.87(0.93-3.74)$

\section{Multivariate Model: Independent predictors of at-risk gambling behaviours}

Multiple linear regression analyses showed that at-risk group, when compared to non-problem gamblers, were more likely to have lost a large sum when first gambling (OR 6.13; $95 \%$ CI 2.73-13.78), more likely to have gambled in reaction to painful life events (OR 22.79; $95 \%$ CI 5.20-99.79) and more likely to think that they have a better chance winning after losing repeatedly (OR 3.10; $95 \%$ CI 1.22-7.91) (Table 4). However, recent phobic disorder, gender, having won a large sum when fist started gambling, having used alcohol or drugs while gambling, having the urge to have a drink in reaction to a painful event and alcohol problem and were not associated to the atrisk group.

Table 4 Multivariate model: Independent correlates of at-risk group

\begin{tabular}{lll}
\hline Correlates & OR (95 \% CI $)$ & $p-$ value \\
\hline Have lost a large sum when first started gambling & $6.13(2.72-13.77)$ & $<.0001^{* * *}$ \\
Have had the urge to gamble in reaction to a painful event & $22.79(5.20-99.79)$ & $<.0001 * * *$ \\
Chance: After losing many times in a row, you are more & $3.10(1.21-7.90)$ & $0.0177^{*}$ \\
likely to win & & \\
\hline
\end{tabular}

$\mathrm{OR}=$ odds ratio, $* p<.05, * * * p<.001$ 


\section{Discussion}

This is the first study to report on gambling behaviors, mental health problems and risk factors in a sample of community-based crack-cocaine injectors and/or smokers. More than half (57\%) of these heavy cocaine users had taken part in gambling activities in the previous year. While the majority reported no or few gambling problems, a significant proportion (10.6\% moderate risk and $7.8 \%$ problem gamblers) reported problems associated with their gambling. Findings are similar to those observed among people addicted to cocaine who are in treatment (Hall et al. 2000; Toneatto and Brennan 2002) and those reported by consumers of alcohol or other drugs in treatment (Barnes et al. 2015). Also, results align with previous studies of active consumers of substances such as the homeless (Nower et al. 2014; Shaffer et al. 2002; Sharman et al. 2015). The present study findings highlight the vulnerability of community-based cocaine users attending homeless and harm reduction programs to gambling problems. Considering nearly one in five cocaine users in this sample suffered from the harmful consequences of gambling activities, it is crucial that the resources they are offered address problems associated with these types of activities (Nower et al. 2014). Research by Holdsworth and Tiyce (2013) has previously emphasized the secretive nature of problems gambling, stemming perhaps from feelings of shame and from associated stigma, which underscores the importance of engaging in proactive efforts to detect them.

Among at-risk gamblers, the most frequently reported gambling activities were VLTs, buying lottery tickets, and buying scratch tickets. Results corroborate previous findings of studies with other vulnerable populations, among whom the problem gamblers reported a preference for VLTs (Antonetti and Horn 2001; Rogers et al. 2005; Shaffer et al. 2002; Talbot 2004). It has been shown that, due to their structural characteristics (Parke and Griffiths 2006; Harrigan 2008) and their availability (Holtgraves 2009), VLTs are often associated to the development of gambling problems (Cox et al. 2005; El-Guebaly et al. 2006). In addition, it is likely that, for these populations, VLTs and buying lottery and scratch tickets are associated with precarious living conditions and lack of resources (Dufour et al., 2014). In such a scenario, gambling is used as a subsistence strategy to gain money and improve one's living conditions (Holdsworth and Tiyce 2013; Shaffer et al. 2002).

Problematic substance use as measured by the SDS for cocaine and the CAGE for alcohol was highly prevalent among study participants, and at-risk gamblers were twice as likely as the non-problem gamblers to have a possible alcohol problem. These concurring addictive disorders point to the complexity of mental health problems among heavy cocaine users which translate clinically into an intricate constellation of needs spanning several other areas of wellbeing such as physical health, and housing (Holdsworth and Tiyce 2013). According to Holdsworth and Tiyce (2013), these compounded needs have an amplifying and accumulating outcome that, over time, generates 
new problems and barriers to the resolution of addictive problems. More research is needed, particularly using longitudinal study design, to better understand the overlapping origins of these problems as well as better intervention approaches.

Although different studies of clinical samples (Fernandez-Montalvo et al. 2012; Mathias et al. 2009; Petry 2005) and in the general population (El-Guebaly et al. 2006; Lorains et al. 2011 for a review) have highlighted higher prevalence of anxiety disorders and depression among problem gamblers, these findings were only partially supported by the present study. In fact, with the exception of phobic disorders, the at-risk group did not differ from non-problem gamblers. A higher prevalence of phobic disorder has also been observed in other at-risk populations such as intravenous drug users (Roy et al. 2015). Furthermore, the fact that more than half gamblers presented an anxiety disorder in the past 12 months, suggests that there may be the underlying mechanism linking anxiety disorders and PG (Desai and Potenza 2008; Kessler et al. 2008; Petry et al. 2005). Impulsivity and difficulty making decisions could also be integral to the mechanisms of these two issues (Gonzales-Ortega et al. 2013; Ochoa et al. 2013). This high comorbidity with mental health problems underlines the necessity of thoroughly assessing the full range of mental health problems whenever someone is seeking help for recovery (Lorains et al. 2011).

In regard to risk factors associated with gambling problems, remembering a large win from when an individual began gambling has been previously associated with the development gambling problems in different studies (Turner et al. 2006; Turner et al. 2008). Still, few studies have underlined the importance of remembering a large loss in one's first gambling experience even though it is likely that such a distressing event, in a population already struggling with financial problems, could rapidly precipitate chasing behavior. Thus, the financial difficulties associated with substance consumption and gambling losses could add to overall stress, potentiating the anxiety disorders and the gambling problems concurrently. Furthermore, as observed in previous studies (Joukhador et al. 2003; Xian et al. 2014), erroneous beliefs pertaining to chance also contributed here to the identification of gambling problems. However, a more extensive evaluation of erroneous beliefs using a validated measurement instrument like the Gamblers's Beliefs Questionnaire (Steenbergh et al. 2002) would help to better understand the importance of this risk factor in the development of gambling problems within this vulnerable group.

Finally, one interesting finding in this study pertains to the variables (mental health, risk factors, sociodemographic) strongly associated with the at-risk group. In fact, the final model indicated that most of the factors that were found to be associated with at-risk group gamblers are emotional components linked to anxiety or to its management. More specifically, having lost a large sum when an individual had first started gambling, having the urge to gamble in reaction to a painful event and having erroneous beliefs about chance are all determinants of the 
at-risk group. This finding is consistent with Jacobs' General Theory of Addictions (Jacobs 1986) and suggests that problematic gamblers use gambling as a maladaptive coping strategy (Gupta and Derevensky 1998). It is therefore possible, for cocaine users, that gambling is used as a way to escape from negative emotional state or distract oneself from distressing thoughts or distressing living conditions (Baker et al. 2004; Kaiser et al. 2012; Koob 2013; Rockloff et al. 2011; Thomas et al. 2009; Wood and Griffiths 2007).

\section{Limitation}

This study has several limitations to be considered including the self-recruitment process, which may have affected the representativeness of the sample. Generalizability of our findings to other populations might be difficult since the study sample was composed of regular cocaine users who either smoked or injected cocaine. They were recruited mainly in community-based programs located in downtown Montréal (i.e., homeless day programs, shelters, and needle exchange programs). Study participants might thus not be representative of all regular cocaine users such as those who do not access these services and those who do not smoke or inject cocaine. Also, data collection by interview-administered questionnaires may have led to the minimization of certain stigmatized behaviors. Recall bias may have occurred because of the broad period of time covered by the questions. Finally, the cross-sectional design could not ascertain causality. A longitudinal follow-up of this cohort will help to better understand the gambling trajectories of cocaine users.

\section{Conclusion}

Despite these limitations, these results underline the presence of a significant proportion of smoked or injected cocaine users exhibiting gambling problems alongside other mental health problems, particularly anxiety problems. These results suggest that gambling may be a strategy to cope with difficult life situations and underline the importance of considering the full range of mental health problems when developing prevention or treatment interventions targeting cocaine users. A initial approach to be considered could be asking community workers to integrate questions on gambling activities as a way to show openness to discuss this topic. Furthermore, cocaine users need integrated plans of intervention to address gambling, drug, alcohol and mental health problems at the same time. In order to do that, it is important that homeless and harm reduction resources have suitable and up to date knowledge of the gambling services offered in their area. Finally, future longitudinal studies need to be 
conducted in order to better understand the relationship between gambling behaviours of cocaine users and the development other at-risk behaviours like injection of substance. They should also expand research to explore the temporal development between substance use disorders, gambling and mental health problems.

\section{Compliance with ethical standards}

Authors do not have any financial or personal relationships with other people or organisations that could inappropriately influence their work. This research involves human participants. All participants gave explicit consented to take part in the study.

\section{Acknowledgements}

The Canadian Institutes of Health Research provided funding. The authors would like to thank the all participants that collaborated in this study and all members of the research team.

\section{References}

Agence de la santé publique du Canada - Previous statistics from the Canadian alcohol and drug use monitoring survey (CADUMS) Highlight report (2011). http://www.hc-sc.gc.ca/hc-ps/drugs-drogues/stat/_2011/summary-sommaire-eng.php. Accessed 15 may 2015.

American Psychiatric Association. (2010). Diagnostic and statistical manual of mental disorders (5th ed., text rev.). Washington, DC: Author.

Antonetti, E., \& Horn, M. (2001). Gambling the home away: A study of the impact of gambling on homelessness. Research report Commissioned by Hanover Welfare Services. Melbourne, Australia: Hanover Welfare Services.

Arseneault, L., Ladouceur, R., \& Vitaro, F. (2001). Jeu de hasard et consommation de substances psychotropes: Prévalence, coexistence et conséquences. Canadian Psychology/Psychologie Canadienne, 42(3), 173. doi: $10.1037 / \mathrm{h} 0086890$

Baker, T. B., Piper, M. E., McCarthy, D. E., Majeskie, M. R., \& Fiore, M. C. (2004). Addiction motivation reformulated: an affective processing model of negative reinforcement. Psychological Review, 111(1), 33.

Barnes, G.M., Welte, J.W., Tidwell, M-C. O. \& Hoffman, J.H. (2015). Gambling and substance use: cooccurence among adults in a recent general population study in the United States. International Gambling studies, 15 (1), 55-71.

Bernadt, M. W., Mumford, J., Taylor, C., Smith, B. \& Murray, R. M. (1982). Comparison of questionnaire and laboratory tests in the detection of excessive drinking and alcoholism. Lancet, 6(8267), 325-328. doi:10.1016/S0140-6736(82)91579-3

Blaszczynski, A., \& Silove, D. (1996). Pathological gambling: Forensic issues. Australian and New Zealand Journal of Psychiatry, 30(3), 358-369.

Conner, K. R., Pinquart, M., \& Holbrook, A. P. (2008). Meta-analysis of depression and substance use and impairment among cocaine users. Drug and Alcohol Dependence, 98(1-2), 13-23. doi:10.1016/j.drugalcdep.2008.05.005 
Cowlishaw, S., \& Hakes, J. K. (2015). Pathological and problem gambling in substance use treatment: Results from the national epidemiologic survey on alcohol and related conditions (nesarc). The American Journal on Addictions. doi:10.1111/ajad.12242

Cowlishaw, S., Merkouris, S., Chapman, A., \& Radermacher, H. (2014). Pathological and problem gambling in substance use treatment: A systematic review and meta-analysis. Journal of Substance Abuse Treatment, 46(2), 98-105.

Cox, B. J., Yu, N., Afifi, T. O., \& Ladouceur, R. (2005). A national survey of gambling problems in Canada. The Canadian Journal of Psychiatry / La Revue Canadienne De Psychiatrie, 50(4), 213-217.

Cunha, P.J., Bechara, A., de Andrade, A.G. \& Nicastri (2010). Decision-making deficits linked to real-life social dysfonction in crack cocaine dependent individuals. The american Journal on Addictions, 20, 78-86.

Cunha, P. J., Nicastri, S., de Andrade, A. G., \& Bolla, K. I. (2010). The frontal assessment battery (FAB) reveals neurocognitive dysfunction in substance-dependent individuals in distinct executive domains: Abstract reasoning, motor programming, and cognitive flexibility. Addictive Behaviors, 35(10), 875-881. doi:10.1016/j.addbeh.2010.05.005

Cunningham-Williams, R. M., Cottler, L. B., Compton, W. M., Spitznagel, E. L., \& Ben-Abdallah, A. (2000). Problem gambling and comorbid psychiatric and substance use disorders among drug users recruited from drug treatment and community settings. Journal of Gambling Studies, 16(4), 347-376.

Currie, S.R., Hodgins, D.C., \& Casey, D.M. (2013). Validity of the Problem Gambling Severity Index interpretive categories. Journal of Gambling Studies, 29(2), 311-327.

Daigre, C., Roncero, C., Grau-López, L., Martínez-Luna, N., Prat, G., Valero, S. \& Casas, M. (2013). Attention deficit hyperactivity disorder in cocaine-dependent adults: A psychiatric comorbidity analysis. The American Journal on Addictions, 22(5), 466-473. doi:10.1111/j.1521-0391.2013.12047.x

Desai, R.A., \& Potenza, M.N. 2008. Gender differences in the associations between past-year gambling problems ans psychiatric disorders. Social Psychiatry and Psychoatric Epidemiology, 43, 173-183.

Dufour, M., Roy, E., Boivin, J-F., Boudreau, J-F., \& Robert, M. (2014). Correlates of at-risk gambling behaviors of homeless youth. Addiction Research and Therapy, S10 (007).

El-Guebaly, N., Patten, S. B., Currie, S., Williams, J. V., Beck, C. A., Maxwell, C. J., \& Wang, J. L. (2006). Epidemiological associations between gambling behavior, substance use and mood and anxiety disorders. Journal of Gambling Studies, 22(3), 275-287. doi: 10.1007/s10899-006-9016-6

Falck, R. S., Wang, J., Carlson, R. G., Eddy, M., \& Siegal, H. A. (2002). The prevalence and correlates of depressive symptomatology among a community sample of crack-cocaine smokers. Journal of Psychoactive Drugs, 34(3), 281-288. doi:10.1080/02791072.2002.10399964

Feigelman, W., Wallisch, L. S., \& Lesieur, H. R. (1998). Problem gamblers, problem substance users, and dualproblem individuals: an epidemiological study. American Journal of Public Health, 88(3), 467-470.

Fernandez-Montalvo, J., Lopez-Goni, J. J. \& Arteaga, A. (2012). Prevalence of pathological gambling in treatment-seeking addicted patients: An exploratory study with the South Oaks Gambling Screen. Anales de Psicología, 28(2), 344-349. doi: 10.6018/analesps.28.2.147611

Ferris, J., \& Wynne, H. (2001). The Canadian problem gambling index. Ottawa, ON: Canadian Centre on Substance Abuse.

Ford, J.D., Gelernter, J., DeVoe, J.S., Zhang, W., Weiss, R.D., Brady, K., Farrer, L. \& Kranzler, H.R. (2009). Association of psychiatric and substance use disorder comorbidity with cocaine dependence severity and treatment utilization in cocaine-dependemt individuals, Drug and Alcohol Dependence, 99, 193-203.

Gainsbury, S. M., Russell, A., Hing, N., Wood, R., Lubman, D. I., \& Blaszczynski, A. (2014). The Prevalence and Determinants of Problem Gambling in Australia: Assessing the Impact of Interactive Gambling and New Technologies. Psychology of Addictive Behavior, 28(3), 769-779. doi: 10.1037/a0036207

Gonzales-Ortega, I., Echeburua, E., Corral, P., Polo-Lopez, R., \& Alberich, S. (2013). Predictors of pathological gambling severity taking gender differences into account. European Addiction Research, 19(3), 146-154. doi: 10.1159/000342311.

Gonzalez-Saiz, F., Domingo-Salvany, A., Barrio, G., Sánchez-Niubó, A., Brugal, M. T., de la Fuente, L., \& Alonso, J. (2009). Severity of dependence scale as a diagnostic tool for heroin and cocaine dependence. European Addiction Research, 15(2), 87-93. doi: 10.1159/000189787 
Gossop, M., Darke, S., Griffiths, P., Hando, J., Powis, B., Hall, W., \& Strang, J. (1995). The Severity of Dependence Scale (SDS): psychometric properties of the SDS in English and Australian samples of heroin, cocaine and amphetamine users. Addiction, 90(5), 607-614. doi: 10.1111/j.13600443.1995.tb02199.x

Gupta, R. \& Derevensky, J.L. (1998). Adolescent gambling behavior: A prevalence study and examinations of the correlates with problem gambling. Journal of Gambling Studies, 14, 319-345.

Hall, G. W., Carriero, N. J., Takushi, R. Y., Montoya, I. D., Preston, K. L., \& Gorelick, D. A. (2000). Pathological gambling among cocaine-dependent outpatients. American Journal of Psychiatry, 157(7), $1127-1133$.

Harrigan, K. A. (2008). Slot machine structural characteristics: Creating near misses using high award symbol ratios. International Journal of Mental Health and Addiction, 6(3), 353-368. doi:10.1007/s11469-0079066-8

Herrero, M. J., Domingo-Salvany, A., Torrens, M., \& Brugal, M. T. (2008). Psychiatric comorbidity in young cocaine users: Induced versus independent disorders. Addiction, 103(2), 284-293. doi:10.1111/j.13600443.2007.02076.x

Holdsworth, L., \& Tiyce, M. (2013). Untangling the complex needs of people experiencing gambling problems and homelessness. International Journal of Mental Health and Addiction, 11(2), 186-198.

Holtgraves, T. (2009). Gambling, gambling activities, and problem gambling. Psychology of Addictive Behaviors, 23(2), 295-302. doi:10.1037/a0014181

Hser, Y., Gelberg, L., Hoffman, V., Grella, C. E., McCarthy, W., \& Anglin, M. D. (2004). Health conditions among aging narcotics addicts: Medical examination results. Journal of Behavioral Medicine, 27(6), 607622. doi:10.1007/s10865-004-0005-x \$

Karila, L., Lowenstein, W., Coscas, S., Benyamina, A., \& Reynaud, M. (2009). Complications of cocaine addiction. La Revue Du Praticien, 59(6), 825-829.

Jacobs, D.F. (1986). A general theory of addictions. A new theoritical model. Journal of Gambling Behavior, 2, 15-31.

Joukhador, J., MacCallum, F., \& Blaszczynski, A. (2003). Differences in cognitive distortions between problem and social gamblers. Psychological Reports, 92(3), 1203-1214. doi:10.2466/PR0.92.3.1203-1214

Kaiser, A. J., Milich, R., Lynam, D. R., \& Charnigo, R. J. (2012). Negative urgency, distress tolerance, and substance abuse among college students. Addictive Behaviors, 37(10), 1075-1083. doi: 10.1016/j.addbeh.2012.04.017

Kandel, D. B., Huang, F., \& Davies, M. (2001). Comorbidity between patterns of substance use dependence and psychiatric syndromes. Drug and Alcohol Dependence, 64(2), 233-241. doi:10.1016/S03768716(01)00126-0

Kessler, R.C., Hwang, I., LaBrie, R., Petukhova, M., Sampson, N.A., Winters, K.C., \& Shaffer, H.J. (2008). DSM-IV pathological gambling in the National Co-morbidity Survey Replication. Psychological Medicine, 38, 1351-1360.

Kessler, R. C. \& Ustun, T. B. (2004). The World Mental Health (WMH) Survey Initiative version of the World Health Organization (WHO) Composite International Diagnostic Interview (CIDI). The International Journal of Methods in Psychiatric Research, 13(2), 93-121. http://www3.who.int/cidi/

King, V. L., Brooner, R. K., Peirce, J., Kolodner, K., \& Kidorf, M. (2014). Challenges and outcomes of parallel care for patients with co-occurring psychiatric disorder in methadone maintenance treatment. Journal of Dual Diagnosis, 10(2), 60-67. doi:10.1080/15504263.2014.906132

Koob, G. F. (2013). Negative reinforcement in drug addiction: the darkness within. Current Opinion in Neurobiology, 23(4), 559-563. doi: 10.1016/j.conb.2013.03.011

Korn, D. A., \& Shaffer, H. J. (1999). Gambling and the health of the public: Adopting a public health perspective. Journal of gambling studies, 15(4), 289-365. doi: 10.1023/A:1023005115932

Kovess, V., Fournier, L., Lesage, A. D., Lebigre, F. A., \& Caria A. (2001). Two validation studies of the CIDIS: a simplified version of the Composite International Diagnostic Interview. Psychiatric Networks, 4, 10-24. 
Lévesque, A., Jutras-Aswad, D., Bertrand, K., Chanut, F., Dufour, M., Lespérance, F., Perreault, M., Vaillancourt, E., \& Roy, E. (2014). Psychological distress increases needle sharing among cocaine users : results from the COSMO study. Journal of Addiction Research and Therapy, S10:003.

Liu, T., Maciejewski, P. K., \& Potenza, M. N. (2009). The relationship between recreational gambling and substance abuse/dependence: data from a nationally representative sample. Drug and Alcohol Dependence, 100(1), 164-168.

Lorains, F. K., Cowlishaw, S., \& Thomas, S. A. (2011). Prevalence of comorbid disorders in problem and pathological gambling: systematic review and meta-analysis of population surveys. Addiction, 106(3), 490-498. doi: 10.1111/j.1360-0443.2010.03300.x

Mathias, A. C. R., Vargens, R. W., Kessler, F. H., \& Cruz, M. S. (2009). Differences in addiction severity between social and probable pathological gamblers among substance abusers in treatment in Rio de Janeiro. International Journal of Mental Health and Addiction, 7(1), 239-249. doi: 10.1007/s11469-0089183-z

Mayfield, D., McLeod, G., \& Hall, P. (1974). The CAGE questionnaire: validation of a new alcoholism screening instrument. American Journal of Psychiatry, 131(10), 1121-1123.

McRae, A. L., Hedden, S. L., Malcolm, R. J., Carter, R. E., \& Brady, K. T. (2007). Characteristics of cocaineand marijuana-dependent subjects presenting for medication treatment trials. Addictive Behaviors, 32(7), 1433-1440. doi:10.1016/j.addbeh.2006.10.007

Nower, L., Eyrich-Garg, K. M., Pollio, D. E., \& North, C. S. (2014). Problem gambling and homelessness: Results from an epidemiologic study. Journal of Gambling Studies. doi:10.1007/s10899-013-9435-0

Ochoa, C., Alvarez-Moya, E.M., Penelo, E., Aymami, M.N., Gómez-Peña, M., Fernández-Aranda, F., Granero, R., Vallejo-Ruiloba, J., Menchón, J.M., Lawrence, N.S., \& al. (2013). Decision-making deficits in pathological gambling: the role of executive functions, explicit knowledge and impulsivity in relation to decisions made under ambiguity and risk. The American Journal on Addiction, 22(5), 492-499.

Papineau, E. (2010). Enjeux de santé publique reliés à l'étatisation des jeux d'argent sur Internet. Retrieved from http://www.college-merici.qc.ca/collection/2010-09-30/etatisation-jeux-argent-sur-internet-enjeux-santepublique.pdf. Accessed 15 may 2015.

Parke, J., \& Griffiths, M. (2006). The psychology of the fruit machine: The role of structural characteristics (revisited). International Journal of Mental Health and Addiction, 4(2), 151-179. doi:10.1007/s11469006-9014-z

Petry, N.M. (2005). Comorbidity of disorderd gambling and other psychiatric disorders. In Pathological gambling: Etiology, comorbidity, and treatment, 85-115. Washington, DC: American Psychological Association.

Petry, N.M., Stinson, F.S., \& Grant, B.F. (2005). Co-morbidity of DSM-IV pathological gambling and other psychiatric disorders: results from the National Epidemiologic Survey on Alcohol and Related Conditions. Journal of Clinical Psychiatry, 66, 564-574.

Petry, N. M. (2007). Gambling and substance use disorders: current status and future directions. The American Journal on Addictions, 16(1), 1-9.

Riezzo, I., Fiore, C., De Carlo, D., Pascale, N., Neri, M., Turillazzi, E., \& Fineschi, V. (2012). Side effects of cocaine abuse: Multiorgan toxicity and pathological consequences. Current Medicinal Chemistry, 19(33), 5624-5646.

Rockloff, M. J., Greer, N., Fay, C., \& Evans, L. G. (2011). Gambling on electronic gaming machines is an escape from negative self reflection. Journal of Gambling Studies, 27(1), 63-72. doi: 10.1007/s10899010-9176-2

Rogers, N., Button, E., \& Hume, A. (2005). Safe as houses: An exploration of the link between gambling and homelessness. Adelaide: South Australian Government Department for Families and Communities.

Roy, E., Justras-Aswad, D., Bertrand, K., Dufour, M., Perreault, M., Laverdiere, E., Bene-Tchaleu, F., \& Bruneau, J. (2015). Anxiety, mood disorders and injection risk behaviors among cocaine users: results from the COSMO study. The American Journal on Addictions (accepted). 
Saunders, E.C., Lambert-Harris, C., McGovern, M.P., Meier, A. \& Xie, H. (2015). Prevalence of posttraumatic stress disorder symptoms among addiction treatment patients with cocaine use disorders. Journal of Psychoactive Drugs, 47(1), 42-50.

Shaffer, H. J., Freed, C. R., \& Healea, D. (2002). Gambling disorders among homeless persons with substance use disorders seeking treatment at a community center. Psychiatric Services, 53(9), 1112-1117.

Shaffer, H. J., \& Hall, M.N. (2001). Updating and refining prevalence estimates of disordered gambling behaviour in the United States and Canada. Revue Canadienne de Santé Publique, 92(3).

Shaffer, H.J., LaPlante, D.A., LaBrie, R.A., Kidman ,R.C., Donato, A.N., \& Stanton, M.V. (2004). Toward a syndrome model of addiction: Multiple expressions, common etiology. Harvard Review of Psychiatry, 12, 367 - 374 . doi: 10.1080/10673220490905705

Sharman, S., Dreyer, J., Aitken, M., Clark, L., \& Bowden-Jones H. (2015). Rates of problematic gambling in a British homeless sample: a preliminary study. Journal of Gambling Studies, 31(2), 525-532.

Smith, J.L., Mattick, R.P., Jamadar, S.D., \& Iredale, J.M. (2014). Deficits in behavioural inhibition in substance abuse and addiction. A meta-analysis. Drug and Alcohol Dependence, 145, 1-33.

Steenbergh, T.A., Meyers, A.W., May, R.K., \& Whelan, J.P. (2002). Development and validation of the Gamblers' Beliefs Questionnaire. Psychology of Addictive Behaviors, 16, 143-149.

Stein, J. A., Grella, C. E., Conner, B. T., \& Gelberg, L. (2012). Addiction syndrome and homelessness. In Shaffer, E., LaPlante, D. A., \& Nelson, S. E. (Eds.), APA Addiction syndrome handbook, Vol. 2: Recovery, prevention, and other issues (pp. 457-471). Doi: 10.1037/13750-000

Steinberg, M. A., Kosten, T. A., \& Rounsaville, B. J. (1992). Cocaine abuse and pathological gambling. The American Journal on Addictions, 1(2), 121-132. doi:10.3109/10550499209004013

Tabachnick, B. G. \& Fidell, L. S. (2001). Using multivariate statistics (4th ed.). Boston, MA: Allyn and Bacon.

Talbot, C. (2004). Gambling and Homelessness. A case management resource, Adelaide (South Australia), UnitingCare Wesley.

Thomas, A. C., Sullivan, G. B., \& Allen, F. C. L. (2009). A theoretical model of EGM problem gambling: More than a cognitive escape. International Journal of Mental Health and Addiction, 7(1), 97-107. doi: 10.1007/s11469-008-9152-6

Toneatto, T., \& Brennan, J. (2002). Pathological gambling in treatment-seeking substance abusers. Addictive Behaviors, 27(3), 465-469.

Turner, N. E., Jain, U., Spence, W., \& Zangeneh, M. (2008). Pathways to pathological gambling: Component analysis of variables related to pathological gambling. International Gambling Studies, 8(3), 281-298. doi:10.1080/14459790802405905

Turner, N., Littman-Sharp, N., \& Zangeneh, M. (2006). The experience of gambling and ist role in problem gambling. International Gambling Studies, 6, 237-266.

Turner, N. E., Preston, D. L., Saunders, C., McAvoy, S., \& Jain, U. (2009). The relationship of problem gambling to criminal behavior in a sample of Canadian male federal offenders. Journal of Gambling Studies, 25(2), 153-169. doi: 10.1007/s10899-009-9124-1

United Nations Office on Drugs and Crime (UNODC) - World Drug Report. (2014). http://www.unodc.org/wdr2014/en/cocaine.html. Accessed 15 may 2015.

Vergara-Moragues, E., González-Saiz, F., Lozano, O. M., Espinosa, P. B., Calderón, F. F., Bilbao-Acebos, I., \& García, A. V. (2012). Psychiatric comorbidity in cocaine users treated in therapeutic community: Substance-induced versus independent disorders. Psychiatry Research, 200(2-3), 734-741. doi:10.1016/j.psychres.2012.07.043

Welte, J. W., Barnes, G.M., Wieczorek, W.F., Tidwell, M-C.O. \& Parker, J.C. (2004). Risk factors for pathological gambling. Addictive Behaviors, 29 (2), 323-335.

Wood, R. T., \& Griffiths, M. D. (2007). A qualitative investigation of problem gambling as an escape-based coping strategy. Psychology and Psychotherapy: Theory, Research and Practice, 80(1), 107-125.

Xian, H., Giddens, J. L., Scherrer, J. F., Eisen, S. A., \& Potenza, M. N. (2014). Environmental factors selectively impact co-occurrence of problem/pathological gambling with specific drug-use disorders in male twins. Addiction, 109(4), 635-644. doi: 10.1111/add.12407 
